\title{
Patients optimizing epilepsy management via an online community
}

\author{
The POEM Study
}

\section{OPEN}

John D. Hixson, MD

Deborah Barnes, PhD, $\mathrm{MPH}$

Karen Parko, MD

Tracy Durgin, PharmD

Stephanie Van Bebber, MSc

Arianne Graham, MBA

Paul Wicks, PhD

Correspondence to

Dr. Hixson:

john.hixson@ucsf.edu
Supplemental data at Neurology.org

\section{ABSTRACT}

Objective: The study objective was to test whether engaging in an online patient community improves self-management and self-efficacy in veterans with epilepsy.

Methods: The study primary outcomes were validated questionnaires for self-management (Epilepsy Self-Management Scale [ESMS]) and self-efficacy (Epilepsy Self-Efficacy Scale [ESES]). Results were based on within-subject comparisons of pre- and postintervention survey responses of veterans with epilepsy engaging with the PatientsLikeMe platform for a period of at least 6 weeks. Analyses were based on both completer and intention-to-treat scenarios.

Results: Of 249 eligible participants enrolled, 92 individuals completed both surveys. Over 6 weeks, completers improved their epilepsy self-management (ESMS total score from 139.7 to 142.7, $p=0.02$ ) and epilepsy self-efficacy (ESES total score from 244.2 to 254.4, $p=0.02$ ) scores, with greatest impact on an information management subscale (ESMS-information management total score from 20.3 to 22.4, p $<0.001$ ). Results were similar in intention-to-treat analyses. Median number of logins, postings to forums, leaving profile comments, and sending private messages were more common in completers than noncompleters.

Conclusions: An internet-based psychosocial intervention was feasible to implement in the US veteran population and increased epilepsy self-management and self-efficacy scores. The greatest improvement was noted for information management behaviors. Patients with chronic conditions are increasingly encouraged to self-manage their condition, and digital communities have potential advantages, such as convenience, scalability to large populations, and building a community support network.

Classification of evidence: This study provides Class IV evidence that for patients with epilepsy, engaging in an online patient community improves self-management and self-efficacy. Neurology ${ }^{\circledR} 2015 ; 85: 129-136$

\section{GLOSSARY}

ESES = Epilepsy Self-Efficacy Scale; ESMS = Epilepsy Self-Management Scale; ICD-9 = International Classification of Diseases, Ninth Revision; ITT = intention-to-treat; PLM = PatientsLikeMe; POEM = Policy for Optimized Epilepsy Management; VISN = Veteran's Integrated Service Network.

Many patients with epilepsy are not well-informed about their condition, ${ }^{1,2}$ and educational programs have been developed to increase health literacy and support self-management. ${ }^{3-5}$ The potential for digital educational programs has long been recognized ${ }^{6}$; however, there remains limited evaluation of their effectiveness. ${ }^{7-9}$ One program, WebEase, used structured educational modules to promote enhanced patient self-efficacy on topics of medication use, sleep, and stress. ${ }^{410-12}$ However, these studies were limited by significant attrition, suggesting that highly structured educational interventions may not be optimally suited for some patients. ${ }^{7,8}$ An alternative approach to formal education is to simply connect patients with one another such that novice

\footnotetext{
From the Departments of Neurology (J.D.H., K.P.), Psychiatry (D.B.), and Epidemiology \& Biostatistics (D.B.), University of California San Francisco and the SF VA Medical Center; US Medical Affairs (T.D.), UCB, Inc.; Northern California Institute for Research and Education and the SF VA Medical Center (S.V.B.); and PatientsLikeMe (A.G., P.W.).

Go to Neurology.org for full disclosures. Funding information and disclosures deemed relevant by the authors, if any, are provided at the end of the article. The Article Processing Charge was paid by PatientsLikeMe.

This is an open access article distributed under the terms of the Creative Commons Attribution-NonCommercial-NoDerivatives License 4.0 (CC BY-NC-ND), which permits downloading and sharing the work provided it is properly cited. The work cannot be changed in any way or used commercially.
} 
patients can benefit from "expert patients" who can suggest practical advice on how to live well with their disease or have better conversations with health care professionals. ${ }^{13,14}$

A patient-powered research network, PatientsLikeMe (PLM), provides an epilepsyspecific support system, as well as digital tools for tracking seizures, symptoms, medications, and comorbidities. An earlier study of the PLM platform suggested that patients experienced self-reported benefits including symptom management, medication adherence, and improved care, with the greatest predictor of benefits being the number of other patients with whom they shared a social connection. ${ }^{14}$ However, this study was a cross-sectional retrospective survey without validated measures.

We sought to conduct a prospective study with a defined population of US veterans with epilepsy using validated survey measures of selfmanagement and self-efficacy to determine the effectiveness of PLM. We hypothesized that an unstructured exposure to PLM would demonstrate statistically significant improvements in both self-management and self-efficacy.

METHODS Primary research question. Does participation in an online patient community improve validated metrics of selfmanagement and self-efficacy in veterans with epilepsy? This study provides Class IV evidence that 6 weeks of participation in a patient-driven, online community increases scoring on validated surveys for epilepsy self-management and self-efficacy. Total survey scores for both self-management $(p=0.02)$ and self-efficacy ( $p=0.02$ ) demonstrated significant improvements; a subscale for information management also demonstrated significant improvement $(p<0.001)$.

Standard protocol approvals, registrations, and patient consents. Approval was obtained from the University of California San Francisco Committee for Human Research Institutional Review Board and the San Francisco VA Medical Center Research \& Development Committee. All participating patients gave informed consent through an online process. Prospective participants entered the study through a Web site, which initially required an e-mail address and unique username. They were presented with an electronic version of the approved informed consent document; an electronic "signature" of approval was required to enter the study, and this action was date- and time-stamped. The trial was registered at www.clinicaltrials.gov (NCT01762215).

Procedures. Potential participants were primarily identified using administrative ICD-9 diagnostic code data for epilepsy and seizures within the Veteran's Integrated Service Network 21 (VISN 21), a region covering the western United States and Pacific, and were contacted by mail and/or phone. Patients were also identified through VA partner hospitals in VISN 17 (Texas) and VISN 6 (Virginia and North Carolina). For the identified cohorts, patient addresses, telephone numbers, and e-mail addresses, if available, were obtained. Per VA research policies, patients were mailed a "Dear Patient" letter inviting them to participate and a prestamped "opt-out" card to decline participation. If the opt-out card was not received back within 3 weeks, investigators attempted to follow up by phone.

Additional participants were recruited through paper and digital advertisement. The Web site www.poemstudy.com provided a study description, participation requirements, and online informed consent process. Eligibility was self-reported using online screening questions, and respondents who were not a US veteran, diagnosed with epilepsy (seizure disorder), or 18 years of age or older were excluded from participation.

Following informed consent, participants created a PLM account and performed baseline assessments. Participants who completed a follow-up assessment around 6 weeks later were given a $\$ 50$ Amazon gift card.

Intervention. In addition to existing epilepsy-specific tracking tools, forums, and educational materials, POEM (Policy for Optimized Epilepsy Management) study participants had the option of receiving a special "veteran" designation, being part of an exclusive veteran discussion forum, and obtaining specialized information about epilepsy care within the VHA Epilepsy Center of Excellence system. Participants engaged with the Web site functions as much or as little as desired during the 6-week study period; participants received newsletter e-mails from PLM but were not contacted by study investigators.

On the basis of a small pilot study $(n=40)$, patient-reported outcomes on perceived self-management skills were assessed using 2 previously validated surveys, which served as co-primary outcome measures: the Epilepsy Self-Efficacy Scale (ESES) and Epilepsy Self-Management Scale (ESMS). ${ }^{11}$ The ESES is a 33-item questionnaire that measures a patient's confidence in managing their own care related to their epilepsy diagnosis and contains 3 subscales: medication management (e.g., compliance), seizure management (e.g., managing triggers), and general management (e.g., attending appointments). An example ESES item reads "I can always take my seizure medication when I am away from home." The survey responses are graded on an 11-point Likert scale, with $0=\mathrm{I}$ cannot do, $5=$ moderately sure I can do, and $10=$ sure I can do (range 0-330). The ESMS is a 38-item scale that assesses a patient's frequency of self-management behaviors and includes 5 subscales: medication (e.g., side effect management), information (e.g., tracking seizures in a diary), safety (e.g., avoiding hazards), seizure (e.g., planning self-care), and lifestyle (e.g., sleep, diet). An example ESMS item reads "I write down how often I have seizures and when they occur." This questionnaire is graded on a 5-point Likert scale, with $1=$ never do and $5=$ always do (range 38-190). Higher scores in both instruments indicate better self-management capabilities.

Using data from the pilot study, we determined a target sample size of approximately 250 participants to adequately test the study hypothesis, assuming an approximate 6-week study completion rate of $40 \%$.

Participants also completed a user satisfaction survey, ${ }^{14}$ which assessed benefits that the platform may provide. Site usage was continually monitored throughout the study, including number of participant logins, posts to a public forum, profile comments to another user, and private messages sent to another user.

Data analysis. Baseline characteristics of the study population were summarized using standard descriptive statistics. Characteristics of completers and noncompleters were compared using $t$ tests for continuous variables and $\chi^{2}$ tests for categorical 
variables. For all survey questions, participants were given the option of answering "not relevant" or "prefer not to answer," and a variety of approaches were used to address missing data. First, analyses were performed using mean Likert scores for all items that were answered in a given scale, ignoring items that were not answered. Second, mean responses from items that were answered were used to calculate extrapolated full-scale and subscale scores. Third, sensitivity analyses were performed excluding participants who replied "not relevant" or "prefer not to answer" for more than $10 \%$ of the items in a given scale. Results were similar using all statistical approaches; therefore, only results using the extrapolated scores are reported in the results section. Our primary analytic approach was maximum likelihood random-effects regression with time as the independent variable. Both intention-to-treat (ITT) and completer analyses were performed. For ITT analyses, we took the conservative approach of assuming zero change for study participants who did not complete the follow-up survey. We decided a priori to use a $p$ value of 0.05 for both of our co-primary outcomes, and to use Bonferroni-corrected $p$ values of 0.01 for the 5 ESMS subscales and 0.0167 for the 3 ESES subscales. Finally, exploratory analyses were performed to identify baseline factors associated with change scores for each of our co-primary outcomes.

All analyses were performed using Stata/SE version 12.1 (StataCorp LP, College Station, TX).

RESULTS A total of 453 individuals registered, of whom 204 were excluded (14 opted out, 51 did not consent, 68 were not veterans, 22 did not have epilepsy, 28 did not complete the initial survey, and 21 were identified as duplicates or invalid) and 249 (55\%) were enrolled (figure). Of 249 enrollees,
$92(37 \%)$ completed the follow-up survey and were included in completer analyses.

The mean age for the eligible participants was 50.2 years (SD 13.9), and approximately $80 \%$ were men (table 1). Most participants (75\%) were non-Hispanic white, more than half were married, and approximately one-quarter had children (table 1). Nearly one-third reported their health status as fair or poor, and nearly two-thirds were not working for pay or were receiving disability income. Completers were slightly more likely than noncompleters to have received education beyond high school ( $83 \%$ vs $72 \%, p=0.055)$ although this was not statistically significant. There were no other demographic or baseline survey scoring differences between completers and noncompleters (table e-1 on the Neurology ${ }^{\circledR}$ Web site at Neurology.org).

We observed statistically significant improvement in both of our co-primary outcomes of the full ESMS (self-management) and ESES (self-efficacy) scores (table 2). ESMS total scores increased 1.1 points $(p=0.02)$ in the ITT analyses and 2.9 points $(p=$ $0.02)$ in the completer analyses. Similarly, ESES total scores increased 3.6 points $(p=0.03)$ in the ITT analyses and 10.2 points $(p=0.02)$ in the completer analyses. The subscale with the greatest improvement was information management (ESMS-IM), which increased 0.9 points in the ITT analyses and 2.1 points in the completer analyses (both $p<0.001$, table 3). The greatest ESES improvement was general

Figure POEM Study participant flowchart

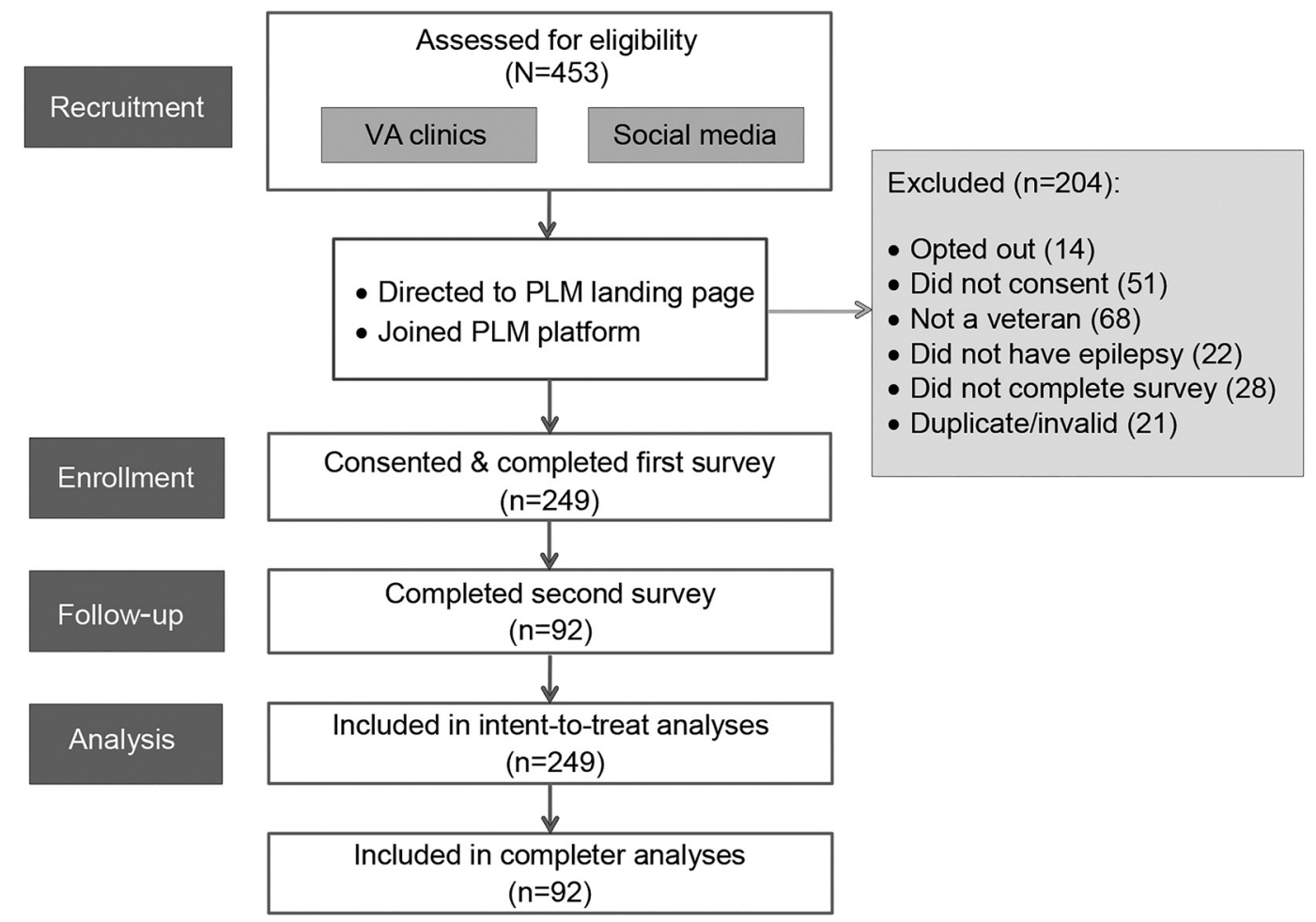

PLM = PatientsLikeMe; POEM = Policy for Optimized Epilepsy Management. 


\begin{tabular}{|c|c|c|}
\hline \multicolumn{3}{|c|}{$\begin{array}{l}\text { Baseline characteristics of } 249 \\
\text { veterans with epilepsy }\end{array}$} \\
\hline \multicolumn{2}{|c|}{ Characteristic } & $\begin{array}{l}\text { Mean } \pm \text { SD or } \\
n(\%)^{\mathrm{a}}\end{array}$ \\
\hline \multicolumn{2}{|l|}{ Age, y } & $50.2 \pm 13.9$ \\
\hline \multicolumn{2}{|l|}{ Male } & $201(80.7)$ \\
\hline \multicolumn{2}{|c|}{ >High school education } & $188(75.8)$ \\
\hline \multicolumn{3}{|c|}{ Race/ethnicity } \\
\hline \multicolumn{2}{|c|}{ Non-Hispanic white } & $187(75.1)$ \\
\hline \multicolumn{2}{|c|}{ Black/African American } & $20(8.0)$ \\
\hline \multicolumn{2}{|c|}{ Hispanic } & $17(6.8)$ \\
\hline \multicolumn{2}{|l|}{ Other } & $25(10.0)$ \\
\hline \multicolumn{2}{|c|}{ Fair/poor self-rated health } & 75 (30.9) \\
\hline \multicolumn{3}{|c|}{ Marital status } \\
\hline \multicolumn{2}{|c|}{ Currently married } & $137(56.2)$ \\
\hline \multicolumn{2}{|c|}{ Widowed/divorced/separated } & 76 (31.1) \\
\hline \multicolumn{2}{|c|}{ Never married } & $31(12.7)$ \\
\hline \multicolumn{2}{|c|}{ Have children } & $66(26.5)$ \\
\hline \multicolumn{3}{|c|}{ Work status } \\
\hline \multicolumn{2}{|c|}{ Full-time } & 47 (19.9) \\
\hline \multicolumn{2}{|c|}{ Part-time } & $35(14.8)$ \\
\hline \multicolumn{2}{|c|}{ Not working for pay } & $154(65.3)$ \\
\hline \multicolumn{2}{|c|}{ Annual household income $<\$ 25,000$} & 77 (35.0) \\
\hline \multicolumn{2}{|c|}{ Receive disability income } & $152(63.6)$ \\
\hline
\end{tabular}

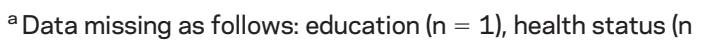
$=6)$, marital status $(n=5)$, work status $(n=13)$, household income $(n=29)$, and disability income $(n=10)$.

self-efficacy, which increased 1.8 points $(p=0.014)$ in ITT analyses and 5.1 points $(p=0.008)$ in completer analyses (table 4).

The median number of logins for completers was 5 (range $0-80$ ). Of this group, $15.2 \%$ posted a comment on the publicly visible forum, $8.7 \%$ left a profile comment on another study member's personal page,

\begin{tabular}{|c|c|c|c|c|c|}
\hline \multirow{2}{*}{$\begin{array}{l}\text { Table } 2 \\
\text { Method }\end{array}$} & \multicolumn{5}{|c|}{ Change over time in co-primary outcomes (ESMS total and ESES total) } \\
\hline & No. & $\begin{array}{l}\text { Preintervention, } \\
\text { mean (SD) }\end{array}$ & $\begin{array}{l}\text { Postintervention, } \\
\text { mean (SD) }\end{array}$ & $\begin{array}{l}\text { Change, mean } \\
(95 \% \mathrm{Cl})\end{array}$ & p Value \\
\hline \multicolumn{6}{|l|}{ ESMS total } \\
\hline ITT & 249 & $138.6(15.9)$ & $139.8(15.6)$ & $+1.1(0.2,2.1)$ & $0.02^{\mathrm{b}}$ \\
\hline Completer & 92 & $139.8(16.9)$ & $142.7(15.4)$ & $+2.9(0.4,5.4)$ & $0.02^{b}$ \\
\hline \multicolumn{6}{|l|}{ ESES total } \\
\hline ITT & 248 & $237.3(58.5)$ & $240.9(58.5)$ & $+3.6(0.3,6.9)$ & $0.03^{b}$ \\
\hline Completer & 92 & $244.2(46.8)$ & $254.4(44.7)$ & $+10.2(1.5,19.0)$ & $0.02^{\mathrm{b}}$ \\
\hline
\end{tabular}

Abbreviations: $\mathrm{Cl}$ = confidence interval; ESES = Epilepsy Self Efficacy Scale; ESMS = Epilepsy Self-Management Scale; ITT = intention-to-treat.

a ITT analyses assume that those who did not complete the second survey experienced no change in scores. Mean change scores and $p$ values based on maximum likelihood randomeffects regression with time as the independent variable.

${ }^{b}$ Significance levels set a priori at $p<0.05$ for both co-primary outcomes. and $29.4 \%$ sent a private message to other members of the PLM community. PLM usage was significantly higher for completers than noncompleters, including median number of logins, posting to forums, leaving profile comments, and sending private messages (table e-2). However, in the completers, number of logins and most other usage statistics were not significantly associated with a change in outcome measures. In exploratory analyses, the only factor that was significantly associated with a change in ESMS or ESES scores was baseline scores, such that scores improved more in participants with lower scores at baseline (i.e., those who had more room to improve). All results were similar in sensitivity analyses that excluded participants who replied "not relevant" or "prefer not to answer" for more than $10 \%$ of the items in a given scale (data not shown).

Table e-3 provides answers to a user satisfaction questionnaire that was administered at the end of the follow-up survey. More than one-fourth of completers said that they had met a new person with epilepsy on the Web site, and 10\% considered this new person to be a friend. Nearly half agreed or strongly agreed that PLM gave them more or better control over their condition and helped them understand their seizures (table e-3).

DISCUSSION We found that veterans with epilepsy who enrolled in an online patient community reported statistically significant improvements in previously validated self-efficacy and self-management measures. The greatest improvement was seen in information management, which includes the use of a seizure diary, tracking side effects, and tools for medication adherence. This result potentially demonstrates that study participants believed that the availability of online tracking tools or social support mechanisms improved their self-management capabilities.

The study demographics were largely reflective of the general US veteran population. The mean age and sex were not unexpected, although we had anticipated that a younger cohort of patients, such as Veterans from Operation Iraqi Freedom and Operation Enduring Freedom, might be more attracted to the concept of a digital health platform. These results indicate that the platform was accepted and used by a broad cohort of patients. Furthermore, there was no demographic difference between study completers and noncompleters, indicating that the older patients participated at the same rate as younger patients (table e-1). Overall, our study population is quite different from the existing nonveteran epilepsy population on PLM, indicating that patients who are offered this type of service through their health care providers might overcome some of the self-selection bias typical of online communities. 


\begin{tabular}{|c|c|c|c|c|c|}
\hline \multirow{2}{*}{$\begin{array}{l}\text { Table } 3 \\
\text { Method }\end{array}$} & \multicolumn{5}{|c|}{ Change over time in ESMS subscales } \\
\hline & No. & $\begin{array}{l}\text { Preintervention, } \\
\text { mean (SD) }\end{array}$ & $\begin{array}{l}\text { Postintervention, } \\
\text { mean (SD) }\end{array}$ & $\begin{array}{l}\text { Change, mean } \\
(95 \% \mathrm{CI})\end{array}$ & $p$ Value \\
\hline \multicolumn{6}{|l|}{ ESMS-IM } \\
\hline ITT & 249 & $19.5(6.9)$ & $20.4(7.1)$ & $+0.9(0.5,1.4)$ & $<0.001^{\mathrm{a}}$ \\
\hline Completer & 92 & $20.3(7.2)$ & $22.4(7.0)$ & $+2.1(0.9,3.3)$ & $<0.001^{\mathrm{a}}$ \\
\hline \multicolumn{6}{|l|}{ ESMS-LM } \\
\hline ITT & 248 & $19.7(4.2)$ & $19.9(4.2)$ & $+0.2(-0.1,0.5)$ & 0.15 \\
\hline Completer & 92 & $20.0(4.2)$ & 20.7 (3.8) & $+0.7(0.02,1.4)$ & 0.04 \\
\hline \multicolumn{6}{|l|}{ ESMS-MM } \\
\hline ITT & 248 & $42.9(6.8)$ & $43.1(6.4)$ & $+0.2(-0.2,0.7)$ & 0.34 \\
\hline Completer & 92 & $42.6(7.4)$ & $43.2(6.3)$ & $+0.6(-0.7,1.8)$ & 0.37 \\
\hline \multicolumn{6}{|l|}{ ESMS-SM } \\
\hline ITT & 249 & $31.1(5.0)$ & $31.0(4.8)$ & $-0.1(-0.4,0.1)$ & 0.36 \\
\hline Completer & 92 & $31.1(5.0)$ & $30.9(4.4)$ & $-0.2(-0.9,0.5)$ & 0.54 \\
\hline \multicolumn{6}{|l|}{ ESMS-SEM } \\
\hline ITT & 248 & 25.5 (3.8) & 25.7 (3.6) & $+0.2(-0.04,0.5)$ & 0.10 \\
\hline Completer & 92 & 25.5 (3.6) & 26.1 (3.2) & $+0.6(-0.1,1.3)$ & 0.12 \\
\hline
\end{tabular}

Abbreviations: $\mathrm{Cl}$ = confidence interval; ESMS = Epilepsy Self-Management Scale; IM = information management; ITT = intention-to-treat; $\mathrm{LM}$ = lifestyle management; $\mathrm{MM}$ = medication management; $\mathrm{SEM}$ = seizure management; $\mathrm{SM}=$ safety management.

Mean change scores and $p$ values based on maximum likelihood random-effects regression with time as the independent variable.

a Statistical significance for ESMS subscale scores was set at $p<0.01$ a priori to account for multiple comparisons.

It was not unexpected that study completers used the platform more throughout the study period, although primarily in a smaller group of users who were highly engaged. These observations are consistent with the previously described trend in online platforms that attract a small cohort of "super-users," while average participants engage less frequently, in a more passive fashion. ${ }^{15}$
About half of our participants agreed that PLM gave them more or better control over their condition and helped them understand their seizures, similar to results seen in an earlier study in a nonveteran population. ${ }^{14}$ Although we did not formally assess the potential for harm, no patient complained of any adverse effects. Site usage was entirely voluntary throughout the study.

\begin{tabular}{|c|c|c|c|c|c|}
\hline Table 4 & Change over & ESES subscales & & & \\
\hline Method & No. & $\begin{array}{l}\text { Preintervention, } \\
\text { mean (SD) }\end{array}$ & $\begin{array}{l}\text { Postintervention, } \\
\text { mean (SD) }\end{array}$ & $\begin{array}{l}\text { Change, mean } \\
(95 \% \mathrm{Cl})\end{array}$ & $p$ Value \\
\hline \multicolumn{6}{|l|}{ ESES-MED } \\
\hline ITT & 242 & $112.6(25.5)$ & $114.2(24.4)$ & $+1.6(-0.1,3.3)$ & 0.06 \\
\hline Completer & 91 & $114.4(22.3)$ & $118.8(17.7)$ & $+4.4(-0.01,8.9)$ & 0.05 \\
\hline \multicolumn{6}{|l|}{ ESES-GEN } \\
\hline ITT & 247 & 67.4 (21.7) & $69.2(21.7)$ & $+1.8(0.4,3.2)$ & $0.014^{a}$ \\
\hline Completer & 92 & 69.2 (19.0) & 74.3 (18.0) & $+5.1(1.3,8.8)$ & $0.008^{a}$ \\
\hline \multicolumn{6}{|l|}{ ESES-SEIZ } \\
\hline ITT & 247 & 57.4 (18.0) & 58.1 (17.9) & $+0.7(-0.1,1.6)$ & 0.09 \\
\hline Completer & 92 & $59.8(14.5)$ & 62.1 (13.9) & $+2.3(0.1,4.5)$ & 0.04 \\
\hline
\end{tabular}

Abbreviations: $\mathrm{Cl}$ = confidence interval; ESES = Epilepsy Self-Efficacy Scale; GEN = general self-efficacy; ITT = intentionto-treat; MED = medication self-efficacy; SEIZ = seizure management self-efficacy.

Mean change scores and $p$ values based on maximum likelihood random-effects regression with time as the independent variable.

a Statistical significance for ESES subscale scores was set at 0.0167 a priori to account for multiple comparisons. 
Although our exploratory analyses did not demonstrate a statistical association between the improved outcomes and engagement on the social elements of the platform, we speculate that these features are worthy of further evaluation. The value of traditional "offline" social support networks for patient selfmanagement has been demonstrated in earlier studies for epilepsy and other chronic conditions. ${ }^{16-19}$ Psychosocial interventions that improve self-management have previously been demonstrated to improve the health of the chronically ill. ${ }^{19-21}$ Furthermore, social interactions have also been directly correlated with improved levels of self-efficacy in the epilepsy population. ${ }^{10}$ Because this study was powered for detecting changes in the primary outcome measures, we believe that it would be inappropriate to conclude that social interactions on the forum did not affect the improvements. In fact, this work supports further hypothesisgeneration and dedicated research on the specific impact of a social network "dose effect" on healthrelated outcomes.

For both the total ESMS and ESES scores, the overall improvements were modest, with the ESMS significance being driven primarily by the information management subscale (table 3 ) and the ESES more by the general self-efficacy subscale (table 4). Information management is more aligned with the features of the PLM platform (tools for condition tracking), and general self-efficacy (overall confidence in health management) is more consistent with the expected benefit of participating in PLM. We also note that our results share similar magnitudes of change when compared with other, more directive and resource-intensive education and diseasemanagement platforms that have utilized the ESMS and ESES measures. ${ }^{7,8}$

With evidence of improved self-management capabilities, it is reasonable to hypothesize that this type of online intervention could positively affect other metrics of epilepsy health, such as health care utilization, morbidity, and even epilepsy-related mortality. For our study, we believed it was premature to examine these outcomes since a foundation of validated research did not yet exist. Based on our results, we think that it would be compelling to explore more objective metrics of epilepsy-related health, such as emergency services utilization, frequency of interactions with epilepsy care teams, and medication adherence. Indirect effects of improved psychosocial support, such as work productivity, absences from work or school, and measures of social integration, might also be interesting measures to investigate.

The study had several limitations including selfreported validation of diagnosis, although most participants were recruited through VA databases and automated detection methods were used to flag suspect registrations. The outcome measures were also self-reported, although they have previously been validated and used in multiple epilepsy studies including controlled trials. Future research into whether clinical outcomes correlate with self-reported behaviors following PLM intervention would be valuable.

The time period of 6 weeks may have been too brief to accurately gauge long-term changes in selfmanagement behaviors. We chose this time period based on the feasibility of engaging patients in the pilot study and on similar studies that used a 6-week trial period. ${ }^{8}$ We aimed for a reasonable balance of exposure, considering that some patients might primarily benefit from an initial online experience while others might establish a longer-term connection through the platform.

We also note that the rate of second survey completion only reached $37 \%$, despite the use of an incentive for full study completion; this might represent an enriched sample of those who benefited from the platform. However, this completion rate was not unexpected based on similar results from a small pilot study conducted in 2012; in fact, the sample size targets for the full protocol were based on an approximate completion rate of $40 \%$. Furthermore, we note that other research studies and reviews in this domain have previously reported similar completion rates ${ }^{11,21}$ over the same time frame, highlighting the expected attrition that occurs with digital interventions. ${ }^{15}$ We have not yet conducted quantitative assessments of the reasons for this attrition, but that exercise would be an appropriate next course. We attempted to statistically control for attrition by assuming no benefit in those who did not complete the second survey for the ITT analysis.

Finally, we acknowledge that we did not include a control group in this investigation because any patient assigned to a "wait list" could access PLM independently outside of the study mechanism, thus exposing the control group to the intervention.

Despite these limitations, we contend that this study provides foundational evidence for the potential benefits of online patient-driven communities and self-management platforms for epilepsy. Traditional medications and other technological interventions will remain essential elements of epilepsy treatment, but there is a growing recognition of the importance of psychosocial support, education, and self-management tools for patients. ${ }^{21}$ Despite this, many patients with epilepsy are not provided with adequate access or resources under our current health care ecosystem; as Mittan $^{21}$ asserts, "the greatest problem among psychosocial treatment and educational programs was that only a handful of these interventions were ever put into general use." He suggests that the economics of reimbursement and the professional time required to 
conduct these interventions impedes widespread adoption. As a cost-effective and more time-efficient alternative, online networks and management platforms offer more ubiquitous accessibility and a larger support system than traditional methods.

If patient engagement is, as some claim, the "blockbuster pill of the 21 st century," 22 how will we support its development and implementation? If digital communities and online self-management tools do have the potential to improve clinical outcomes, then we have a shared responsibility to rethink our current health care ecosystem, focusing on new methods for incentivizing interventions that are proven to benefit patients.

\section{AUTHOR CONTRIBUTIONS}

John D. Hixson: corresponding author, study concept, design, and overall supervision. Deborah Barnes: author, data analysis and interpretation. Karen Parko: author, critical revision of the manuscript for content. Tracy Durgin: author, study concept, design, and critical revision of manuscript. Stephanie Van Bebber: author, study coordination, data analysis and interpretation. Arianne Graham: author, study coordination, design, and data analysis. Paul Wicks: author, study concept, design, data analysis and interpretation.

\section{ACKNOWLEDGMENT}

The authors thank the staff and clinicians at the Houston and Durham VA Medical Center Epilepsy Centers for their substantial contributions to the recruitment efforts. The authors also thank Kate Bertko, John Haupert, and Kelly Bertenthal for their assistance with the organization and conduct of the study.

\section{STUDY FUNDING}

Funding for this project was provided by a research grant from UCB, Inc., and managed through the Northern California Institute for Research and Education, San Francisco.

\section{DISCLOSURE}

J. Hixson received research support from UCB Pharma Inc. as the principal investigator for this study. In addition, he has previously received research support from the American Epilepsy Society and the American Academy of Neurology. Dr. Hixson also receives consulting fees from Lumetra Healthcare Solutions and the California Medical Board. D. Barnes received support for research study design and analysis services from UCB Pharma Inc. for the current study. She is also supported by research grants from the NIH (R01 AG045043); Department of Veterans Affairs (1IO1HX000694: REA 01097); Department of Defense (W81XWH-11-2-0189); Patient-Centered Outcomes Research Institute (CDR-1306-01500); Brain \& Behavior Foundation (formerly NAR$\mathrm{SAD}$ ); and philanthropic funds through the Osler Center for Integrative Medicine and the S.D. Bechtel, Jr. Foundation. K. Parko reports no disclosures relevant to the manuscript. T. Durgin is an employee of UCB, Inc., which funded the study. S. Van Bebber reports no disclosures relevant to the manuscript. A. Graham is an employee of PatientsLikeMe and holds stock options in the company. She has received speaker fees from the Cleveland Clinic and CenterWatch. The PatientsLikeMe research team has received research funding (including conference support and consulting fees) from AbbVie, Acorda, Actelion, Amgen, AstraZeneca, Avanir, Biogen, Boehringer Ingelheim, Genzyme, Janssen, Johnson \& Johnson, Merck, Novartis, Sanofi, and UCB. The PatientsLikeMe Research and Development team has received research grant funding from Kaiser Permanente, the Robert Wood Johnson Foundation, Sage Bionetworks, The AKU Society, and the University of Maryland. P. Wicks is an employee of PatientsLikeMe and holds stock options in the company. Dr. Wicks is an associate editor at the Journal of Medical Internet Research, is on the editorial advisory board for the BMJ, and has received speaker fees from Bayer. The PatientsLikeMe research team has received research funding (including conference support and consulting fees) from AbbVie, Acorda, Actelion, Amgen, AstraZeneca, Avanir, Biogen, Boehringer Ingelheim, Genzyme, Janssen, Johnson \& Johnson, Merck, Novartis, Sanofi, and UCB. The PatientsLikeMe Research and Development team has received grant funding from Kaiser Permanente, the Robert Wood Johnson Foundation, Sage Bionetworks, The AKU Society, and the University of Maryland. Go to Neurology.org for full disclosures.

Received October 29, 2014. Accepted in final form March 18, 2015.

\section{REFERENCES}

1. Long L, Reeves A, Moore JL, Roach J, Pickering C. An assessment of epilepsy patients' knowledge of their disorder. Epilepsia 2000;41:727-731.

2. Coker MF, Bhargava S, Fitzgerald M, Doherty CP. What do people with epilepsy know about their condition? Evaluation of a subspecialty clinic population. Seizure 2011; 20:55-59.

3. May TW, Pfafflin M. The efficacy of an educational program for patients with epilepsy (MOSES): results of a controlled, randomized study. Epilepsia 2002;43: 539-549.

4. Dilorio C, Escoffery C, Yeager KA, et al. WebEase: development of a Web-based epilepsy self-management intervention. Prev Chronic Dis 2009;6:A28.

5. Bradley P, Lindsay B. Care delivery and self-management strategies for adults with epilepsy. Cochrane Database Syst Rev 2008;(1):CD006244.

6. Hoch DB, Norris D, Lester JE, Marcus AD. Information exchange in an epilepsy forum on the World Wide Web. Seizure 1999;8:30-34.

7. Pramuka M, Hendrickson R, Zinski A, Van Cott AC. A psychosocial self-management program for epilepsy: a randomized pilot study in adults. Epilepsy Behav 2007;11: 533-545.

8. Dilorio C, Bamps Y, Walker ER, Escoffery C. Results of a research study evaluating WebEase, an online epilepsy self-management program. Epilepsy Behav 2011; 22:469-474.

9. Haut SR, Hall CB, Borkowski T, Tennen H, Lipton RB. Modeling seizure self-prediction: an e-diary study. Epilepsia 2013;54:1960-1967.

10. Dilorio C, Shafer PO, Letz R, et al. Behavioral, social, and affective factors associated with self-efficacy for selfmanagement among people with epilepsy. Epilepsy Behav 2006;9:158-163.

11. Dilorio C, Escoffery C, McCarty F, et al. Evaluation of WebEase: an epilepsy self-management web site. Health Educ Res 2008;24:185-197.

12. Shegog R, Bamps YA, Patel A, et al. Managing Epilepsy Well: Emerging e-tools for epilepsy self-management. Epilepsy Behav 2013;29:133-140.

13. Wicks P, Massagli M, Frost J, et al. Sharing health data for better outcomes on PatientsLikeMe. J Med Int Res 2010; 12:e19.

14. Wicks P, Keininger DL, Massagli MP, et al. Perceived benefits of sharing health data between people with epilepsy on an online platform. Epilepsy Behav 2012;23:16-23.

15. Eysenbach G. The law of attrition. J Med Internet Res 2005;7:e11.

16. Robinson E, DiIorio C, DePadilla L, et al. Psychosocial predictors of lifestyle management in adults with epilepsy. Epilepsy Behav 2008;13:523-528. 
17. Gallant MP. The influence of social support on chronic illness self-management: a review and directions for research. Health Educ Behav 2003;30:170-195.

18. Walker ER, Bamps Y, Burdett A, Rothkopf J, Dilorio C. Social support for self-management behaviors among people with epilepsy: a content analysis of the WebEase program. Epilepsy Behav 2012;23:285-290.

19. Walker ER, Engelhard G, Barmon C, et al. A mixed methods analysis of support for self-management behaviors: perspectives of people with epilepsy and their support providers. Epilepsy Behav 2014;31:152-159.
20. Lorig KR, Ritter PL, Laurent DD, Plant K. Internet-based chronic disease self-management: a randomized trial. Med Care 2006;44:964-971.

21. Mittan RJ. Psychosocial treatment programs in epilepsy: a review. Epilepsy Behav 2009;16:371-380.

22. Wicks P, Hixson J. The patient engagement pill: lessons from epilepsy. In: New Era of Patient Engagement: Health Affairs Invited Blog Commentary. 2013. Available at: http:// healthaffairs.org/blog/2013/02/07/the-patient-engagement-pilllessons-from-epilepsy/; archived at: http://www.webcitation. org/6VOqIhqQ7. Accessed January 7, 2015.

\section{This Week's Neurology ${ }^{\circledR}$ Podcast}

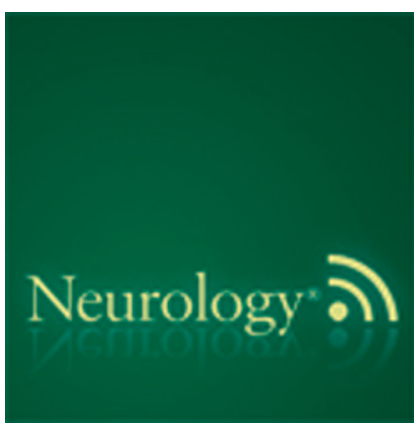

Early EEG contributes to multimodal outcome prediction of postanoxic coma (see p. 137)

This podcast begins and closes with Dr. Robert Gross, Editor-inChief, briefly discussing highlighted articles from the July 14, 2015, issue of Neurology. In the second segment, Dr. Andy Schomer talks with Dr. Jeannette Hofmeijer about her paper on early EEG contributing to multimodal outcome prediction of postanoxic coma. Dr. Sarah Wesley reads the e-Pearl of the week about Susac syndrome. In the next part of the podcast, Dr. Alberto Espay focuses his interview with Dr. Daniel Lowenstein on his H. Houston Merritt Lecture at the AAN Annual Meeting on the topic of advances in the treatments for epilepsy.

Disclosures can be found at Neurology.org.

At Neurology.org, click on "RSS" in the Neurology Podcast box to listen to the most recent podcast and subscribe to the RSS feed.

CME Opportunity: Listen to this week's Neurology Podcast and earn 0.5 AMA PRA Category 1 CME Credits ${ }^{\mathrm{TM}}$ by answering the multiple-choice questions in the online Podcast quiz.

\section{Share Your Artistic Expressions in Neurology 'Visions'}

AAN members are urged to submit medically or scientifically related artistic images, such as photographs, photomicrographs, and paintings, to the "Visions" section of Neurology ${ }^{\circledR}$. These images are creative in nature, rather than the medically instructive images published in the NeuroImages section. The image or series of up to six images may be black and white or color and must fit into one published journal page. Accompanying description should be 100 words or less; the title should be a maximum of 96 characters including spaces and punctuation.

Learn more at www.aan.com/view/Visions, or upload a Visions submission at submit.neurology.org. 


\section{Neurology}

Patients optimizing epilepsy management via an online community: The POEM Study John D. Hixson, Deborah Barnes, Karen Parko, et al.

Neurology 2015;85;129-136 Published Online before print June 17, 2015

DOI 10.1212/WNL.0000000000001728

This information is current as of June 17, 2015

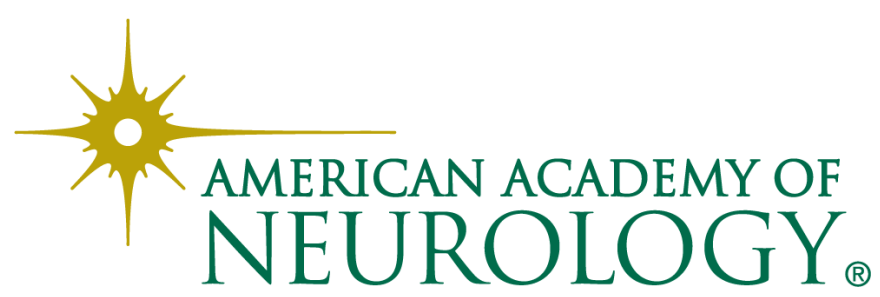




\section{Updated Information \& Services}

\section{Supplementary Material}

References

Citations

Subspecialty Collections

Permissions \& Licensing

\section{Reprints}

including high resolution figures, can be found at: http://n.neurology.org/content/85/2/129.full

Supplementary material can be found at: http://n.neurology.org/content/suppl/2015/06/17/WNL.0000000000001 728.DC1

This article cites 20 articles, 0 of which you can access for free at: http://n.neurology.org/content/85/2/129.full\#ref-list-1

This article has been cited by 1 HighWire-hosted articles: http://n.neurology.org/content/85/2/129.full\#\#otherarticles

This article, along with others on similar topics, appears in the following collection(s):

All Clinical trials

http://n.neurology.org/cgi/collection/all_clinical_trials

All Epilepsy/Seizures

http://n.neurology.org/cgi/collection/all_epilepsy_seizures

All Health Services Research

http://n.neurology.org/cgi/collection/all_health_services_research Models of care

http://n.neurology.org/cgi/collection/models_of_care

Outcome research

http://n.neurology.org/cgi/collection/outcome_research

Information about reproducing this article in parts (figures,tables) or in its entirety can be found online at:

http://www.neurology.org/about/about_the_journal\#permissions

Information about ordering reprints can be found online:

http://n.neurology.org/subscribers/advertise

Neurology ${ }^{\circledR}$ is the official journal of the American Academy of Neurology. Published continuously since 1951, it is now a weekly with 48 issues per year. Copyright @ 2015 American Academy of Neurology. All rights reserved. Print ISSN: 0028-3878. Online ISSN: 1526-632X.

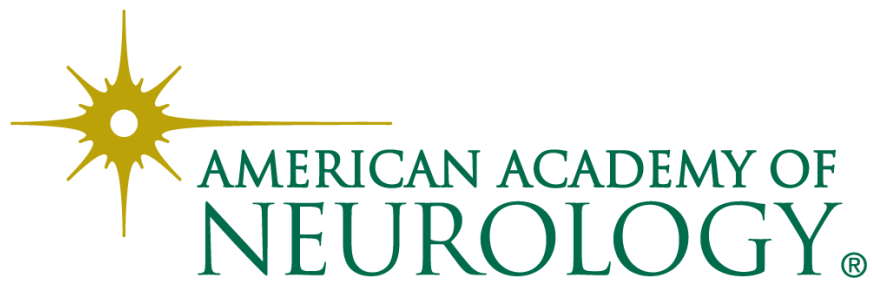

